\title{
Policies towards a more efficient car fleet
}

\author{
Svante Mandell ${ }^{\star}$ \\ $v t i-$ Swedish National Road and Transport Research Institute
}

\begin{abstract}
Transportation within the EU, as in most of the industrialized world, shows an increasing trend in $\mathrm{CO}_{2}$ emissions. This calls for measures both to decrease the amount of transportation and/or to increase the efficiency in the vehicle fleet. The present paper addresses the latter by providing a simple and transparent analytical model that illustrates how different policy measures address different parts of an interlinked system, which determines the composition of the future car fleet. Apart from being simple, and thereby providing an intuitive framework, the model highlights the difference between initial responses to policies and the outcome in equilibrium both in the short and the long run.
\end{abstract}

KEYWORDS: Vehicle, fuel-efficiency, policy

\section{ACKNOWLEDGEMENT}

Financial support by the Swedish Energy Agency and CTS-Centre for Transportation Studies is gratefully acknowledged. The paper has benefitted from suggestions by Roger Pyddoke.

^ e-mail: svante.mandell@vti.se 


\section{Introduction}

In latter years, global warming has become a central policy topic throughout most of the industrialized world. The EU has put battling climate change high on the agenda and has introduced a series of measures, most notable perhaps the emissions trading scheme (EU ETS) that covers $\mathrm{CO}_{2}$-emissions from the energy intensive industry in the EU. One of the more troublesome sources of $\mathrm{CO}_{2}$-emission in the $\mathrm{EU}$ is transportation. The EU's transport sector shows an increase in $\mathrm{CO}_{2}$-emissions between 1990 and 2006 of 34.9\%. This should be seen in the light of that non-transport $\mathrm{CO}_{2}$-emissions from EU15 (excluding bunker fuels) has decreased by $9.4 \%$ over the same period. The share of $\mathrm{CO}_{2}$-emissions stemming from transportation, excluding bunker fuels, has thus been steadily rising, from $17 \%$ in 1990 to 23\% in 2006 (European Federation for Transport and Environment, 2008). A major cause for this is the substantial increase in the use of fossil fuel in road transportation, $25 \%$ between 1990 and 2006 (EEA, 2008). Similar trends are seen also outside the EU. In the US for instance the transport sector has, according to the US department of transportation, increased its $\mathrm{CO}_{2}$ emissions by $28.6 \%$ (excluding bunker fuels) between 1990 and $2004^{1}$.

There are several ways to curb this trend. Basically, we may divide the possible measures into two groups. One group contains measures aiming to decrease the amount of fossil fuel based transportation. This may entail decreasing transportation as a whole, e.g., by facilitating more efficient logistic solutions, and/or strive for a modal shift, e.g., transfer transportation from road to rail which produces less $\mathrm{CO}_{2}$-emissions. The second group, which will be in the present paper's focus, includes measures aiming for more fuel efficient road transports. Obviously, these two groups are not exclusive. Most likely it is beneficial to target both the amount of transports as well as the way they are carried out. Furthermore, many policy measures will target both groups. A fuel tax, for instance, yields incentives both to decrease the amount of transportation and to increase the fuel efficiency of the vehicles used.

\footnotetext{
${ }^{1}$ EPA (2006) provides a good overview of greenhouse gas emissions from the US transport sector.
} 
This paper addresses policy instruments with potential to improve the efficiency of the passenger car fleet ${ }^{2}$. The aim is to provide a analytical model, which illustrates that the improvements of the car fleet may be achieved in several different ways due to the complexity of the situation. The model will facilitate the understanding of how different policy measures interact with each other. Something that, given the numerous different policy measures presently used, seems to be of great importance for policy makers.

The model presented in this paper does not aspire on being a substitute for advanced simulation and CGE models as those often used as prediction tools today ${ }^{3}$. Rather, it is meant to complement them in the sense that while those models clearly are better equipped to simulate reality their complexity often makes them less transparent and understandable.

The remaining paper is structured as follows. The next section describes the model. Section 3 contains an overview of policy measures currently used within the EU. As many policy measures are to be designed and implemented by the individual member states, we use Sweden as an example. Sweden is particularly interesting as it has a heavy and fuel consuming car fleet compared to other EU member states. Section 4 discusses the policy measures in terms of the model. As an illustration, a crude calibration of the model is carried out in section 5 using the Swedish situation 2007. Section 6 concludes.

\section{The Model}

The model focuses on the interaction between different "markets" that are involved in changing the car fleet. It is inspired by DiPasquale and Wheaton (1992) that describes the market for real estate assets and space. In that case there is a rental market for office space that is interlinked with a market for real estate assets. In the present case, there are no such distinct markets. The approach is nevertheless applicable as it captures the steps behind a

\footnotetext{
${ }^{2}$ The paper does not explicitly address trucks, buses or other vehicles in the transport sector. However, the basic reasoning in the paper easily could be applied to these as well.

${ }^{3}$ de Jong et.al. (2002) contains a somewhat dated overview of vehicle choice models used in practice in Europe. A recent study by Fang (2008) clearly illustrates the complexity of modern statistical simulation models and also contains references to earlier studies.
} 
transition from a less energy efficient car fleet to a more efficient one. More importantly, it is well suited to illustrate the driving forces behind such a transition.

There are four distinct steps in the model, each of which may be target for one or several policy instruments. The first step captures the relationship between the efficiency in the existing car fleet and the cost of transportation. The second step maps the costs of transportation to a willingness to pay for more efficient cars. The third step involves the car manufacturers' response to the willingness to pay in terms of providing more efficient new cars. The fourth, and final, step captures the speed of transition, i.e., the impact on the existing car fleet from a change in efficiency of new cars. Each step will be discussed in more detail below, starting with Step 1.

\subsection{Step 1 - transportation cost}

This step captures the obvious relationship that a less fuel efficient vehicle induces a higher cost per unit of transportation. Let $e$ denote average fuel efficiency measured as an average of $\mathrm{CO}_{2}$ emissions per $\mathrm{km}$ transportation in the existing car fleet. Let $f(e)$ be a function that maps the average fuel efficiency to cost per km transportation. It seems reasonable that in most current situations the costs stem from the fuel prices and, thus, $f(e)$ is linear in $e$. However, it is not impossible to design policy measures that cause the relationship to be non-linear even though it would seem to require a more complicated scheme that must rely on measures additional to the fuel price. For now, let

$$
f(e)=a+b^{*} e
$$

where $a$ and $b$ are parameters. Note that $f(e)$ measures costs on a per transportation unit basis. That is, it does not capture the effect changes in fuel prices will have on the amount of transportation being carried out. Also note that, as $e$ is measured as the fuel efficiency of the average car in the existing fleet, $f(e)$ is the cost for this average car.

\subsection{Step 2 - willingness to pay for a more efficient vehicle}

This step focuses on the willingness to pay for a new vehicle with a given fuel efficiency. The basic concept is that if the new vehicle is more fuel efficient than the average one in the existing fleet, the average willingness to pay for the more efficient alternative should increase in the existing cost per transportation unit. There are several problems associated with this as fuel efficiency is only one of several characteristics that influence the willingness to pay. To 
further complicate the situation, some of the other important characteristics are likely to be negatively correlated with fuel efficiency. For example, a representative consumer is probably willing to pay more for a car with a higher level of safety but this is likely to increase the weight of the car, which in turn will increase its fuel consumption. For the sake of this model it suffices to assume that the willingness to pay increases in efficiency ceteris paribus, that is keeping all other relevant characteristics constant.

There are several variables that may influence how the transportation cost maps to willingness to pay. One such is the use of the car, if the car is to be used extensively, i.e., to travel long distances, the willingness to pay given a transportation cost per distance should increase. As we do not focus on the impact on transportation as such, we do not explicitly deal with this aspect. Another variable is the discount rate. This is important as the car will be used over a longer time period and the willingness to pay thus must relate to the present value of potential savings due to increased fuel efficiency. There are also potential policy instruments to be considered, namely those that are targeted towards the vehicle as such (rather than directly towards the fuel consumption). Some policy instruments may cause the relationship between transportation cost and willingness to pay to be non-linear. For simplicity, we nevertheless assume a linear relation given by:

$$
g(f)=\alpha+\beta^{*} f
$$

where $g(f)$ denotes the willingness to pay for a more efficient vehicle and $\alpha$ and $\beta$ are parameters.

\subsection{Step 3 - Car manufacturers' response}

This step in the model illustrates how car manufacturers respond to the consumers' willingness to pay. Rather than seeking a standard supply curve, we are interested in the impact of willingness to pay on average fuel efficiency among new cars. The underlying concept is simply that the more (the representative) consumers are willing to pay for switching to fuel efficient vehicles; the more efficient cars will be produced. To capture this let $h(g)$ be a linearly decreasing function that measures the average emissions, in terms of emissions per transportation unit, e.g., $\mathrm{g} \mathrm{CO}_{2} / \mathrm{km}$, for new cars:

$$
h(g)=l-m^{*} g
$$


where $l$ and $m$ are parameters.

\subsection{Step 4 - the speed of transition}

This step measures the impact on the existing car fleet from a change in efficiency among new cars. Again, the basic concept is simple; the more fuel efficient are new vehicles, the more efficient the car fleet. There are however other aspects influencing this relationship. For instance the turn-over rate in the vehicle fleet. As in step 1 to 3 , let us for simplicity assume a linear relationship:

$$
e(h)=r+s * h
$$

where $r$ and $s$ are parameters.

\subsection{Closing the model}

The four steps are illustrated graphically in Figure 1. The figure is drawn such that the market is in equilibrium in the sense that there are no forces working to change the fuel efficiency of the existing car fleet. This is seen by following the broken line through steps 1 to 4 and noting that it ends up in the same point as it originates from, i.e., $e(h)$ takes on the same value as $e_{0}$. That is, even if there are new vehicles entering the market, the average efficiency of them is such that the average efficiency of the fleet remains unchanged. 




Figure 1. Graphical illustration of the model.

Substituting through all steps yields an expression for the equilibrium average efficiency in the car fleet as

$$
e_{e q b m}=\frac{r+s l-s m(\alpha+\beta a)}{1+s m \beta b}
$$

Equation (5) thus yields the average emission level of the car fleet when it has adjusted so that there are no longer any forces working to change this level, i.e., the system is in equilibrium.

\section{Existing policy instrument - the case of the EU and Sweden}

The EU member states all regulate $\mathrm{CO}_{2}$-emissions from their transportation sector. However, there are substantial differences between member states regarding regulation design. There are potential benefits with harmonizing this, e.g., by introducing one common fuel tax level throughout the EU. This has also been discussed and proposed in the debate, see for instance EC (2005). Very few of these proposals have been implemented, mostly due to that taxes are each individual member state's responsibility. At present there are two implemented EU directives of particular interest for this paper; the energy tax directive (Council Directive 2003/96/EC), and the labelling directive (Council Directive 1999/94/EC). The former 
specifies the minimum tax levels for fossil fuel over a ten year period starting 2004 . The directive is generally perceived as being rather weak as most member states already have tax levels exceeding those specified in the directive. The latter directive stipulates that new passenger cars must carry an information label specifying the car's fuel consumption and $\mathrm{CO}_{2}$ emissions ${ }^{4}$. There is also the Eurovignette directive (Council Directive 1999/62/EC), which specifies common rules on distance-related tolls and time-based user charges for the use of certain infrastructure, e.g., motorways, tunnels and bridges. This however only concerns heavy goods vehicles (above 12 tonnes) and is therefore of less interest here.

Apart from these directives, the policy instruments geared towards transportation in general and the car fleet in particular is up to each member state to design. Most member states use similar instruments, but their strengths - e.g. the applied tax levels - differ between states. We will here examine Sweden. As previously noted, Sweden is of some certain interest in that it has, in comparison to other member states, a heavy and highly fuel consuming car fleet.

As all other member states, Sweden applies a fuel tax. Somewhat unique to Sweden, this tax has two components. The first is called "energy tax". Even though this suggests it being a tax on the fuel's energy content, this is not the case. Calibrating the energy tax to take the energy content into account would, for instance, increase the tax on diesel relative to petrol. However, as it is often claimed that the energy tax should internalise negative externalities, such as non-greenhouse gas emissions, noise etc., that are not obviously dependent on energy content, such calibrations do not seem to be motivated.

The second component is called " $\mathrm{CO}_{2}$-tax". This tax is directly tied to the carbon content of different fuels, and thus differs per volume unit for, say, diesel and petrol. The $\mathrm{CO}_{2}$-tax corresponds to just above $€ 100$ per tonne $\mathrm{CO}_{2}$. As the carbon content in the fuel is directly linked to the $\mathrm{CO}_{2}$ emissions that will occur when the fuel is used, this tax is highly efficient in the sense that it is directly targeting the emissions as such.

When it comes to "green" fuels, as ethanol and RME, they are subject neither to the $\mathrm{CO}_{2}$-tax nor to any energy tax. The former seems reasonable given the construction and purpose of the

\footnotetext{
${ }^{4}$ The effectiveness of the labelling directive has been questioned. The commission is currently working on a proposal to amend some of the problems with the original directive.
} 
$\mathrm{CO}_{2}$-tax. The latter is not as obvious and is probably best regarded as a subsidy on alternative fuels. These tax exemptions are to remain at least until 2013.

There are special tax rules for fuel used in the agricultural sector as well as for maritime transportation and railways. Given the scope of the present paper we do not discuss these here.

Many countries have launched ECO-driving campaigns, aiming at providing information about how to use cars in a more fuel efficient way, e.g., the ECODrivingUSA-campaign in the US or the ACT $\mathrm{CO}_{2}$ in the UK which also targets other ways to decrease $\mathrm{CO}_{2}$ emissions. These campaigns, as the labelling directive, thus belong to the group of informative policy instrument.

The measures above primarily target Step 1 in the model. We now turn to policy instruments that are directly geared towards the vehicle, i.e., Step 2 in the model. One example of such an instrument is a tax on sales and/or registration of cars. Since 2001, Sweden does not levy any sales or registration tax on cars (apart from the standard VAT). There are a few other member states that do not use such taxes, e.g., the UK, Germany, France and Luxembourg. Other member states show a wide variety of tax constructions ranging from a simple flat rate, as in Italy, to more complex solutions based on cylinder volume etc, as in the Netherlands, Greece and Ireland. The vehicle registration tax has come under scrutiny mostly due to its impact on the internal market. The problem being that the tax hinders trade in passenger cars between member states for end consumers. The European Commission has proposed that the registration tax should be abolished over a transition period of five to ten years (SEC(2005) 809).

Most member states levy an annual circulation tax on cars. As with the other policy instruments, the way this tax is designed varies among member states. In many states the tax differs between diesel and petrol vehicles. Differentiation with respect to the size of the engine is also frequently used. Many member states tie the annual circulation tax to fuel consumption or $\mathrm{CO}_{2}$ emissions directly. Sweden belongs to the latter group. For vehicles that fulfil the requirements of the Euro 4 standard or are newer than 2005 the tax is based on $\mathrm{CO}_{2}$ emissions. The tax contains a fixed rate of 360 Swedish kronor $(\sim € 36)$ plus 15 Swedish kronor for each gram of $\mathrm{CO}_{2}$ emissions exceeding $100 \mathrm{~g} / \mathrm{km}$. For diesel cars, this is multiplied by 3.15 for cars from 2008 or later and by 3.3 for cars older than this. 
Sweden also applies a system where purchase of an "environmental friendly car" is associated with a subsidy of 10000 Swedish kronor $(\sim € 1000)$. To be considered "environmental friendly" a car must fulfil at least one of the following requirements: a) emissions must not exceed $120 \mathrm{~g} / \mathrm{km}, \mathrm{b}$ ) the car may run on alternative or flexible fuel with a maximum consumption limits dependent on fuel, or c) the car run on electricity with a maximum consumption of $37 \mathrm{kwh} / 100 \mathrm{~km}$. This system was intended to be in place until 2010 . However, due to an unexpectedly large number of sales of cars fulfilling the requirements, the system will be abolished already in mid 2009 .

On top of these instruments there are important policy instruments geared towards company cars, i.e., cars owned by a company but used by one of its employees. Again taking Sweden as an example, the rules surrounding the taxation of company cars are very complex. The basic implications of these rules, however, is that given that an employee may be granted a company car it is beneficial - from a tax perspective - to choose a car with a purchasing price around $€ 30000$. This favours relatively heavy and fuel consuming vehicles, incidentally such as those traditionally produced by the Swedish car manufacturers Volvo and Saab. Looking at new registrations of Volvos and Saabs in Sweden 2006, more than 70\% of these were company cars, (TemaNord, 2008). Typically these cars are owned by the company over three years after which they are sold. Thus, it seems plausible that these rules have had a significant impact on the composition of the Swedish car fleet.

We now turn to policy instruments focusing on the car manufacturers, i.e., targeting Step 3 in the model. Currently, there are few policy instruments directed towards car manufacturers in the EU. In 1998 the European Automobile Manufacturers Association (ACEA) signed a voluntary agreement with the European Commission ${ }^{5}$. The agreement had as a target to reach a level of average emissions from new cars of $140 \mathrm{~g} \mathrm{CO}_{2} / \mathrm{km}$ by 2008 . The agreement also aimed at reaching average emissions of $120 \mathrm{~g} \mathrm{CO}_{2} / \mathrm{km}$ by $2012\left(130 \mathrm{~g} \mathrm{CO}_{2} / \mathrm{km}\right.$ through improved motor technology and an additional $10 \mathrm{~g}$ through other measures, e.g., tires, airconditioning systems and reduced carbon content in fuel). Regarding the 2012 target, the commission has stated that "in the absence of additional measures, the EU objective of $120 \mathrm{~g}$ $\mathrm{CO}_{2} / \mathrm{km}$ will not be met at a 2012 horizon" and that the Commission considers it "necessary to resort to a legislative approach [...] for instance through fiscal incentives and green public

\footnotetext{
${ }^{5}$ Similar agreements have been written with the Japanese (JAMA) and Korean (KAMA) car industry.
} 
procurement” (COM(2007) 19 Final, p. 7). A compromise was reached on December 1, 2008, which implies that only $65 \%$ of the cars must fulfil the $120 \mathrm{~g} \mathrm{CO} 2 / \mathrm{km}$ target by 2012 . This share will gradually increase to $100 \%$ by 2015 . Manufacturers not meeting these targets will have to pay a fine designed such that small deviations yield smaller fines per gram than large deviations.

Other types of instruments that would provide fiscal incentives include a trading scheme where producers of vehicles that emit more than some threshold value will have to buy permits from producers of vehicles that emit less and so called feebate systems where low emitting vehicles are subsidized while vehicles with high emissions are levied a fee. A feebate system may be designed so that the fees finance the subsidies, see Greene et.al. (2005).

The last group of policy instruments to be addressed here is targeted towards scrapping vehicles and thus influences Step 4 in the model. Again, policies differ between member states. In Sweden up until mid 2007, scrapping vehicles that fulfilled certain requirements, e.g., being from 1998 or older, entitled the owner of the vehicle a scrap premium. At present, the scrap premium in Sweden is abolished and there seems to be no plans on replacing it with a new system. Italy has an approach that directly targets the substitution of an old inefficient vehicle with a new one. The basic concept is that the consumer is provided with a tax incentive of $€ 800$ and a two year exemption from the annual circulation tax when purchasing a new vehicle that fulfils the Euro 4 or 5 exhaust emissions standard if, simultaneously, an old vehicle that fulfils the Euro 0 or 1 standard is scrapped.

\section{Using the model to illustrate policy instrument}

Let us now turn to using the model to illustrate the impact of policy instruments aimed at achieving a more fuel efficient - less $\mathrm{CO}_{2}$ producing - car fleet. We examine policy instruments that influence each step respectively, starting with Step 1.

\subsection{Policy instruments influencing Step 1}

As discussed above, a central policy instrument for curbing emissions from road transports is fuel taxes. Even though the primary function of a fuel tax perhaps is to reduce the amount of transportation, we are here interested the secondary effect such a tax will have on the efficiency of the car fleet. Figure 2 illustrates the effects of increasing a fuel tax. The direct effect is that $b$ increases and thus $f(e)$ will become steeper, as emitting an additional unit $\mathrm{CO}_{2}$ 
now is more costly. Given the initial composition of the car fleet, captured by $e_{0}$, the cost per kilometre transportation thus increases, which results in that consumers put a higher value on a more efficient vehicle. In response to this, car manufacturers will supply more efficient cars and the car fleet will, as an average, become more efficient. Even though this story clearly is based on simplifying assumptions it allows us to focus on the resulting efficiency of the vehicle fleet, denoted $e_{1}$ in Figure 2.

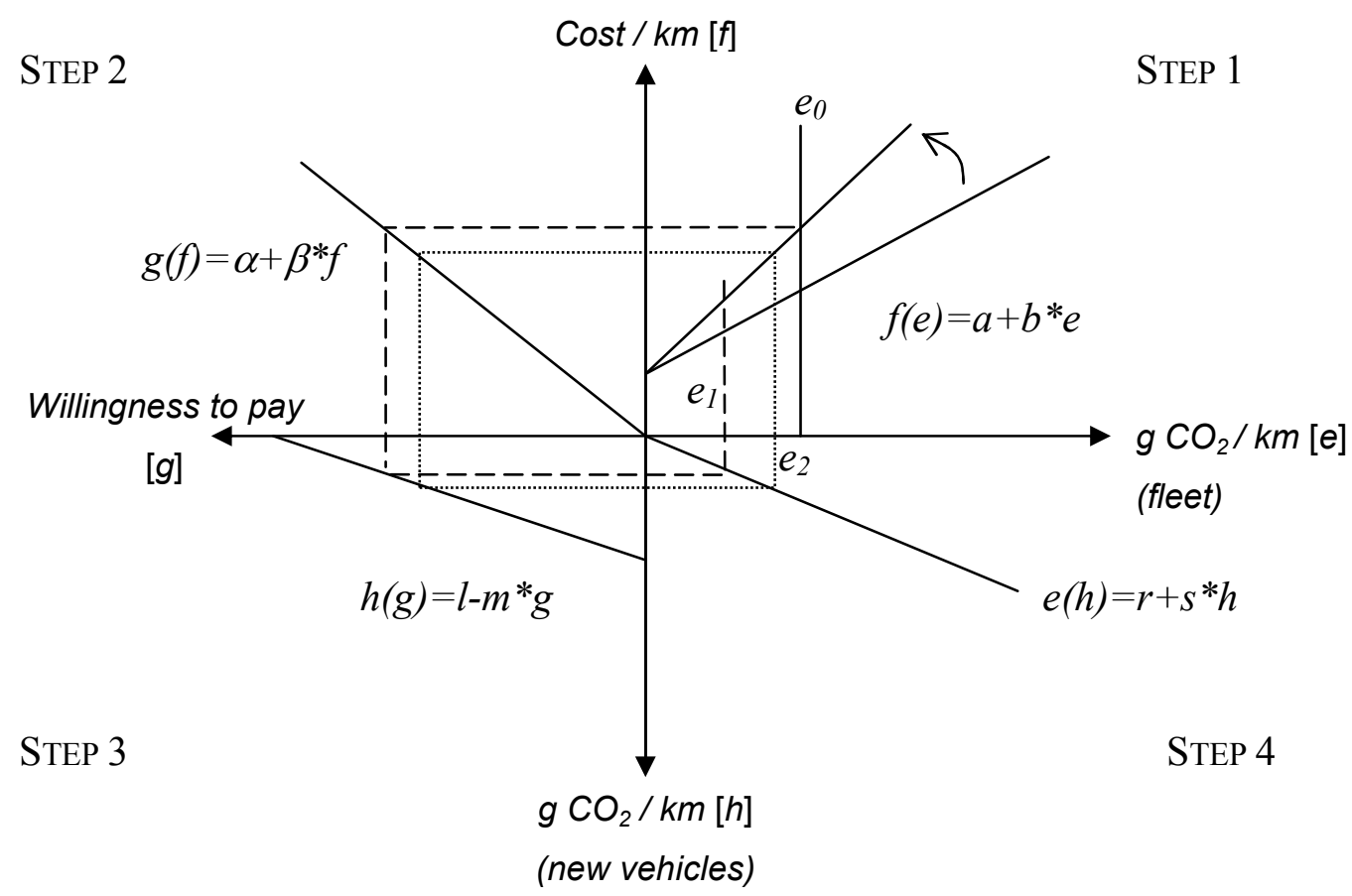

Figure 2. Effects of increased fuel taxes

If it was the case that the vehicle fleet, due to the increased fuel tax, reaches a new composition with an average efficiency given by $e_{1}$ the average cost per $\mathrm{km}$ is significantly lower than the average cost under the initial efficiency, $e_{0}$. As a matter of fact, it is so low that that the average consumer's willingness to pay does not justify the car manufacturers to supply vehicles with such a high level of efficiency. That is, given a fleet fuel efficiency of $e_{1}$, the model suggests that the car fleet should become less efficient.

The model does not explicitly capture the dynamics of the transition, but it seems reasonable that an increased fuel tax will spur a process that may take some time. During this process, some consumers choose to buy a new and more efficient car. We have no way of knowing 
which consumers this will be, but it seems probable that cars on the low end of the efficiency distributions, i.e., the cars that are least efficient, are replaced by new cars from the other side of the distribution, thus increasing the average efficiency of the fleet. This means that the average willingness to pay for more efficient vehicles is decreasing under the transition phase. At some point, namely when the average efficiency of the fleet equals $e_{2}$, the average willingness to pay is such that it exactly sustains the equilibrium and we would expect no further changes in average efficiency. That is, the transition will not go all the way down to $e_{1}$, rather it will stop when it reaches $e_{2}$ since at that point - given the higher fuel tax - there are no forces working to change the average efficiency of the vehicle fleet and the system is at a new equilibrium.

As noted, another group of policy instruments that influences Step 1 are campaigns for ecodriving. Such campaigns aim at decreasing the $\mathrm{CO}_{2}$ emissions per kilometre given the existing car fleet. In terms of the model this will result in $f(e)$ being flatter. Even though this is good from an emissions perspective, it does not provide incentives to invest in more efficient vehicles. On the contrary, the campaign will start a process that eventually will lead to a new equilibrium consisting of a less efficient car fleet than before the campaign ceteris paribus. A plausible conclusion from this is that eco-driving campaigns are likely to result in a short-run decrease in emissions but for this effect to remain the campaign should be coupled by other policy instruments, e.g., increased fuel taxes, such to avoid the adverse long-run effect on the vehicle fleet.

\subsection{Policy instruments influencing Step 2}

This step maps the cost of transportation to willingness to pay for a more efficient vehicle. Thus, policy instruments central for this step include financial instruments like subsidies for efficient cars and $\mathrm{CO}_{2}$-differentiated vehicle taxes, i.e., taxes that do not influence the cost per driven distance as those handled in Step 1.

Figure 3 illustrates the example of a differentiated annual circulation tax. Giving the $\mathrm{CO}_{2}$ component of the annual circulation tax more weight corresponds to increasing $\beta$ and consequently the curve in Step 2 will become less steep. This implies that, at a given cost / km resulting from Step 1, the average consumer's willingness to pay for a more fuel efficient vehicle will be higher. This, in Step 3, creates a response among car manufacturers to produce more efficient cars, which through Step 4 will influence the composition of the car fleet. Just 
as was the case with the fuel tax discussed above, we see from Figure 3 that the initial effect (illustrated by broken lines) exaggerates the expected effect. Rather, once the composition of the car fleet starts to move towards a more efficient state, the impact from the differentiated annual circulation tax becomes less. Thus, we would expect to see a more efficient car fleet over time, as illustrated by the dotted lines, but the impact of the tax differentiation will be less than suggested by the initial effect.



Figure 3. Effects of a differentiated annual circulation tax with lower tax for more efficient vehicles

Informative measures as a clear labelling system of new cars are also examples of policy instruments that would influence this step of the model. Such policies make it easier for consumers to make informed and, in some sense, more correct choices. That is, a given cost per kilometre in Step 1, may yield a different willingness to pay for a more efficient vehicle if the consumers receive better information of different vehicles' fuel efficiency.

\subsection{Policy instruments influencing Step 3 and 4}

Policy instruments that target the third step of the model include instruments geared directly towards the manufacturers. As discussed above, at present there are few such instruments motivated by $\mathrm{CO}_{2}$, the main one being the voluntary agreement to reach $140 \mathrm{~g} / \mathrm{km}$ as an 
average $\mathrm{CO}_{2}$ emissions level from new cars by 2008/2009. Also mentioned above, the European Commission believes that there is a need for fiscal policy instruments targeting car manufacturers in order to decrease average emissions even further. The purpose of such policy instruments, in terms of the model, would be to reach a lower emission level $\left[\mathrm{g} \mathrm{CO}_{2}\right.$ $/ \mathrm{km}$ ] for any given level of consumers' willingness to pay. This is achieved either through decreasing $l$ or increasing $m$ or a combination of these two. A policy instrument designed as a subsidy that is higher for vehicles that emit less will increase $m$. Depending on the more exact design of such a subsidy, it may also influence the value of $l$.

The fourth part of the model maps the average emissions from new vehicles to average emissions in the fleet. One primary driving force behind this step is the turnover rate of vehicles, which depends on the expected average life span of a car. One class of instruments directly geared towards this step contains those that target scrapping of old inefficient vehicles, e.g., the system formerly used in Sweden or currently used in Italy.

In terms of the model, a policy instrument aimed towards scrapping old inefficient cars will decrease $s$. This results in that more efficient new cars will have a stronger impact on the existing car fleet in terms of average $\mathrm{CO}_{2}$ emissions per $\mathrm{km}$. It should be noted that this is valid in the short run. Over the long run all vehicles will eventually be replaced even without further incentives. We will return to this issue in the subsequent numerical illustration.

\section{A numerical illustration}

The purpose of the model described above is to illustrate and to provide an intuitive framework for how different policy instruments may target different parts of the car market and how this influences the fuel efficiency of the car fleet. That is, the model is not primarily a simulation tool. Even so, we will in this section calibrate the model, trying to capture the characteristics of the Swedish car market and the transition to a more fuel efficient fleet we currently observe in Sweden. It must be stressed that the calibration will be very crude as it mainly serves as an illustration to provide a better understanding of the model.

A crucial driving force in the model is that consumers are willing to pay for a more efficient vehicle ceteris paribus. Thus far it has not been necessary to specify exactly what is meant by "a more efficient vehicle". Let us here define it as a vehicle that emits no $\mathrm{CO}_{2}$ at all. The exact definition is not crucial as it only introduces a scaling factor in the model. Thus, we could have used some other definition, e.g., a vehicle that fulfils the requirement of $120 \mathrm{~g} \mathrm{CO}_{2} / \mathrm{km}$. 
Clearly, the point of reference chosen is a highly hypothetical one, as it - in terms of the model - amounts to a vehicle that induces zero cost per $\mathrm{km}$. The reason for using such a hypothetical reference case is that it, without loss of generality, allows us to normalize $f(e)$ and $g(f)$ such that they go through the origin. That is, $a$ and $\alpha$ are both zero.

To keep the presentation simple, let the fuel cost (measured as petrol price including taxes ${ }^{6}$ ) be the only thing that influences the cost per $\mathrm{km}$. The average price for 1 litre of 95 octane petrol in Sweden in 2007 was 11.53 SEK. We may transform the amount of $\mathrm{CO}_{2} / \mathrm{km}$ to litres by noting that burning one litre of petrol releases $2.36 \mathrm{~kg} \mathrm{CO}_{2}$ into the atmosphere ${ }^{7}$. In Sweden 2007, average emissions in the fleet amounted to $222 \mathrm{~g} \mathrm{CO}_{2} / \mathrm{km}$ (The Swedish Road Administration, 2008). Let us denote this $e_{2007}$. By these figures we may estimate the average cost per $\mathrm{km}$ in the car fleet, relative to the hypothetical zero emission vehicle, to be 1.08 $\mathrm{SEK} / \mathrm{km}$. This yields that $b=0.0045$.

In Step 2, we are interested in turning the $1.08 \mathrm{SEK} / \mathrm{km}$ into a willingness to pay. That is, given the average cost per $\mathrm{km}$, how much more would a consumer, on average, be willing to pay for a zero emission vehicle as compared to the average vehicle currently in the fleet? This requires a few bold assumptions regarding the estimated life span of a new car, how far it will run each year and the discount rate. Thus, assume that the average estimated life span of a car is 10 years, that it will run on average $13000 \mathrm{~km}$ per year ${ }^{8}$ and that a reasonable real interest rate amounts to $4 \%$. Furthermore, assume that a consumer planning on buying a car in 2007 views the present petrol price as a reasonably good approximation of the real fuel prices the coming 10 years. All these assumptions are questionable, but probably not completely off target. The present value of driving $13000 \mathrm{~km}$ each year for 10 years at a cost of 1.08 $\mathrm{SEK} / \mathrm{km}$ amounts to approximately $114000 \mathrm{SEK}$, which is thus the additional willingness to

\footnotetext{
${ }^{6}$ As the price of petrol is closely linked to the price of diesel, we use only the former in the model. An alternative would be to use a weighted average, but this would only result in a scaling effect that would have only minor impact on the outcome.

${ }^{7}$ The exact number depends on the composition of the petrol and may thus vary slightly. This value corresponds to the one used in Kågeson (2005).

${ }^{8}$ This is approximately the average annual driving distance for petrol cars in Sweden, for diesel cars this value is higher.
} 
pay for a zero emissions vehicle as compared to one of average efficiency given the assumptions used. This corresponds to a value on $\beta$ of 105442 .

The third step of the model is the most complicated one to estimate. From above we have the willingness to pay of 114000 SEK and we know that the average new car sold in Sweden under 2007 emitted $181 \mathrm{~g} \mathrm{CO}_{2} / \mathrm{km}$ (The Swedish Road Administration, 2008). Thus, from equation (3) we have that $181=l-m * 114000$. However, we have no good way of knowing the values of $l$ and $m$ respectively. We may nevertheless argue that even if fuel prices were zero there must be an upper bound on the average emissions from new cars. Looking at today's market and disregarding the most extreme and luxurious vehicles, large and heavy cars, as for instance Chrysler Grand Voyager, emit between 250 and $300 \mathrm{~g} \mathrm{CO}_{2} / \mathrm{km}$. The most fuel consuming version of the Volvo V70 emits $270 \mathrm{~g} \mathrm{CO}_{2} / \mathrm{km}$. As these cars are generally expensive even without considering their fuel consumption, it seems reasonable that even if fuel prices were zero they should be in the upper part of the car fleet distribution. Thus, a crude guess may be that average emissions under a zero fuel price may be $250 \mathrm{~g} \mathrm{CO}_{2} / \mathrm{km}$. If one accept this guess we have that $l=250$ and, thus, $m=0.0006$.

Finally, in the fourth step we directly see that the car fleet is currently in a transition towards a more fuel efficient state since the average emissions rate from new cars is lower than that of the fleet. As the system obviously is not in equilibrium, we cannot calibrate it as if it were, i.e., we cannot estimate the values on $r$ and $s$ such that the fuel efficiency reaches the starting point of $222 \mathrm{~g} \mathrm{CO}_{2} / \mathrm{km}$. If we adopt a long run view, we may ignore the current composition of the car fleet by arguing that in the long run both current vehicles and, at least some, new vehicles will be replaced. That is, under the long run view we may set $r$ to zero and $s$ to 1 , which implies that if the car manufacturers only provide cars that, on average, emit $181 \mathrm{~g} \mathrm{CO}_{2}$ $/ \mathrm{km}$ this will also be the average emissions in the fleet once the entire fleet has been replaced.

To address the impact of policy instruments in the short run, say in one year, requires an assumption about the share of the fleet likely to be replaced during this period. Let us assume that every new vehicle, on average emitting $181 \mathrm{CO}_{2} \mathrm{~g} / \mathrm{km}$, replaces an average vehicle in the fleet, emitting $222 \mathrm{CO}_{2} \mathrm{~g} / \mathrm{km}$. Then $s$ in (4) denotes the share of vehicles in the fleet being replaced. We have already made an assumption about the expected life time of a car being 10 years. A point of departure is thus to assume that $10 \%$ of the fleet is replaced each year. This will probably underestimate the effect of the policy instruments since it seems likely that those vehicles that are taken out of the fleet are those with emissions above average. To 
somewhat compensate for this, we may assume a higher value on $s$ to capture that even if $10 \%$ of the number of vehicles are replaced the share is larger when taking emissions in consideration $^{9}$. Thus, let us assume $s=15 \%$ and, consequently, $r=85 \% * 222=188.7$.

This concludes the calibration of the model. We may now use the model to predict the equilibrium fuel efficiency in the future car fleet, keeping in mind the series of simplifying assumptions made along the way. Let us start with the short term model, i.e., where $s=0.15$ and $r=188.7$. The expected average emission level in equilibrium per $\mathrm{km}$ in 2008 (as the model is calibrated on data from 2007) may be calculated by equation (5) using the parameter values specified above. This yields (note that due to the way the model is normalized the term within brackets is zero):

$$
e_{e q b m}^{2008}=\frac{r+s l-s m(\alpha+\beta a)}{1+s m \beta b}=\frac{188.7+0.15 * 250}{1+0.15 * 0.00060 * 105442 * 0.0049}=216.1
$$

Two things are worth noting regarding this estimate. First, the emissions level in equilibrium (216.1) is very close to the value achieved if equilibrium effects are ignored (215.9) ${ }^{10}$. This suggests that, in the short run, the market is close to being in equilibrium. Second, the estimated decrease in $\mathrm{g} \mathrm{CO}_{2} / \mathrm{km}$ compared to 2007 is $2.7 \%$, which is in line with the observed decrease between 2006 and 2007 of $2.4 \%$. This may serve as an indication that the calibration is not too far from reality.

The long run equilibrium is perhaps more interesting as it addresses the question what the car fleet will emit if the current policy measures (and all other underlying parameters, e.g., oil prices and available technology) are maintained at the present level. Using $r=0$ and $s=1$ in equation (5) gives the long run equilibrium as:

$$
e_{e q b m}^{L R}=\frac{r+s l-s m(\alpha+\beta a)}{1+s m \beta b}=\frac{250}{1+0.00060 * 105442 * 0.0049}=190.7
$$

\footnotetext{
${ }^{9}$ A drawback with this approach is that the share of vehicles being replaced intuitively should be endogenous also in the short run.

${ }^{10}$ This figure is reached simply by entering the calibrated values of $s$ and $r$ into (4).
} 
This result is illustrated in Figure 4, which also shows the mechanisms at work. Given the current situation, the average new car emits $181 \mathrm{~g} \mathrm{CO}_{2} / \mathrm{km}$. This obviously implies that, as new cars are replacing old ones in the fleet, average emissions in the fleet declines. However, this results in that the average cost $/ \mathrm{km}$ and consequently the average willingness to pay for more efficient vehicles will also decline. As a result the fleet's average will not reach 181 $\mathrm{g} \mathrm{CO}_{2} / \mathrm{km}$. Rather, it will stabilize at the higher level of $190.7 \mathrm{~g} \mathrm{CO}_{2} / \mathrm{km}$, which thus is the long run equilibrium illustrated by the dotted line in Figure 4.

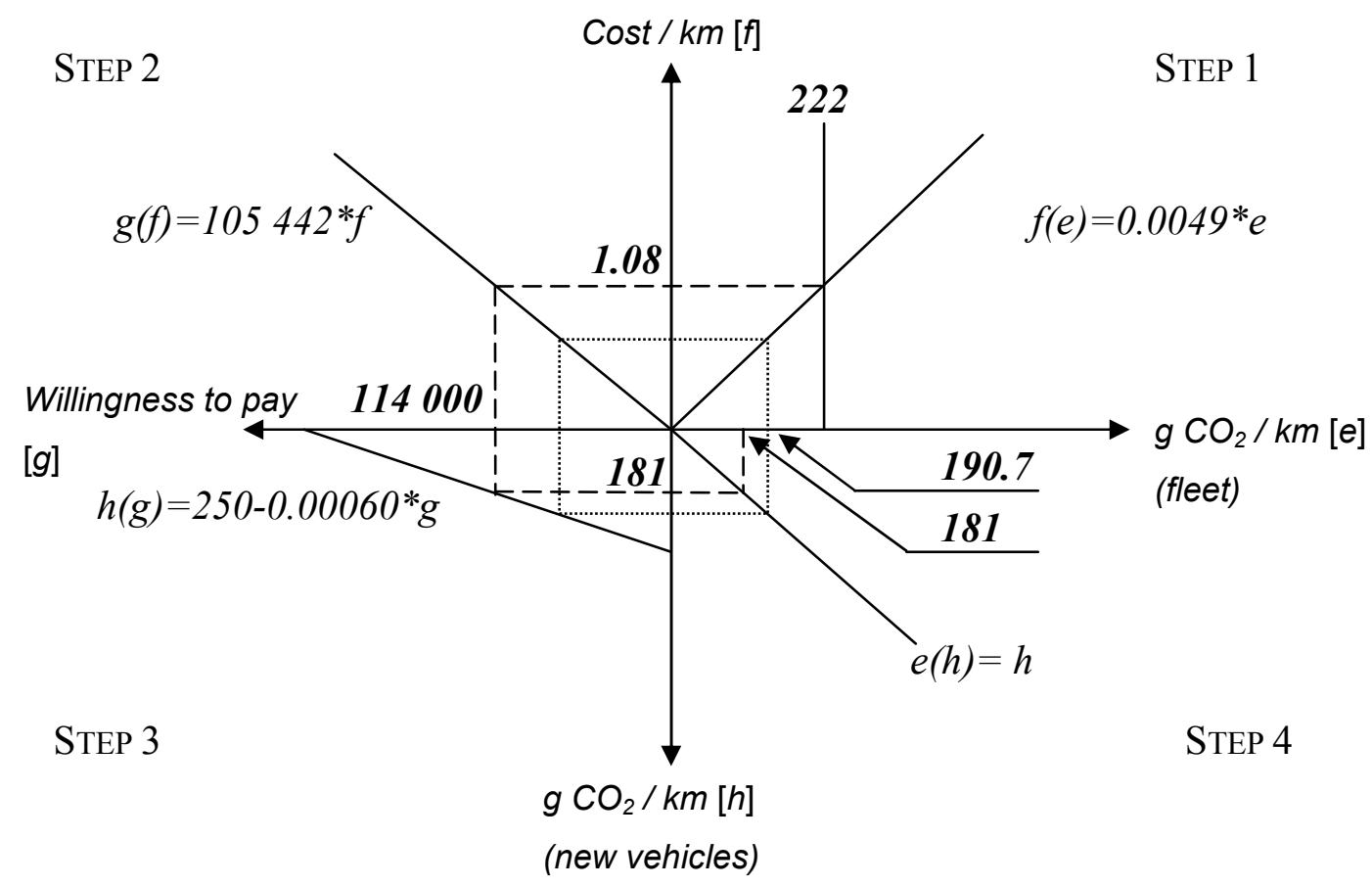

Figure 4, the long run calibrated model.

As $190.7 \mathrm{~g} \mathrm{CO}_{2} / \mathrm{km}$ is far from the EU target, this suggests that there is a need for further and/or stronger policy instruments if the target is to be reached. From the discussion above it should be clear that there are several ways to further incentivize an increase in fuel efficiency all of which will influence the model. One possible policy would be to increase the fuel tax. Say, for instance, that the fuel tax is increased so that the price of petrol corresponds to 15 SEK/litre (which is approximately the highest price observed in Sweden 2008, even though that followed from high oil-prices rather than increased fuel taxes). In terms of the model, a fuel price of $15 \mathrm{SEK} /$ litre will yield a higher $b$, i.e., a steeper line in Step 1. This will carry through into a higher willingness to pay for a more efficient vehicle (the initial effect yields a willingness to pay of $\sim 149000 \mathrm{SEK}$ ), which results in more efficient vehicles being sold (the initial effect is that the average new car will emit $\left.\sim 160 \mathrm{CO}_{2} \mathrm{~g} / \mathrm{km}\right)$. As above, these initial 
effects exceed the effects that constitute the equilibrium. In the short run, equation (5) suggests that the car fleet, given the higher fuel price, will emit $213 \mathrm{~g} \mathrm{CO}_{2} / \mathrm{km}$ on average. As expected, the impact on the car fleet is larger in the long run. Again using (5) and the higher fuel price, the estimated average in the long run will be $178 \mathrm{~g} \mathrm{CO}_{2} / \mathrm{km}$ in equilibrium.

Similar exercises can be conducted for each policy instrument or combination of instruments. For example, the same long run equilibrium as induced by the 15 SEK petrol price may be achieved by keeping the petrol price on the 2007 level of $11.53 \mathrm{SEK} /$ litre and applying a policy instrument to increase $\beta$ to 137188 . This would for instance be achieved by applying a $\mathrm{CO}_{2}$ based annual circulation tax such that it increases the average yearly cost as compared to the zero emission reference vehicle by 3200 SEK. As a last illustration, let us apply both the annual circulation tax and the higher fuel tax. This results, according to the model, in a short run equilibrium of $210 \mathrm{~g} \mathrm{CO}_{2} / \mathrm{km}$ and a long run equilibrium of $164 \mathrm{~g} \mathrm{CO}_{2} / \mathrm{km}$.

The calibration in this numerical illustration is very crude, so the exact figures are of minor interest. Even disregarding the exact outcome, it may be perceived as painting a somewhat grim picture in that, even when assuming a rather high fuel price for instance, the improvement in average efficiency in equilibrium tends to be quite small given the EU target of $120 \mathrm{~g} \mathrm{CO}_{2} / \mathrm{km}$. There are however reasons to believe that the actual effects may be greater than suggested by this illustration. For instance, the average efficiency of new cars in 2007 $\left(181 \mathrm{~g} \mathrm{CO}_{2} / \mathrm{km}\right)$ has been taken as the initial effect resulting from fuel prices etc. for 2007. This may be a plausible assumption, but given that we look at a system currently in transition it seems reasonable that the $181 \mathrm{~g} \mathrm{CO}_{2} / \mathrm{km}$ is, at least partly, a consequence of circumstances that occurred earlier than 2007. That is, if anything, $181 \mathrm{~g} \mathrm{CO}_{2} / \mathrm{km}$ may be greater than the true initial effect and, thus, the equilibrium levels calculated above may exceed the true ones.

Another matter, perhaps of greater importance, follows from the model's limited capability of handling dynamics. This is particularly true for Step 3, where it seems reasonable that the car manufacturing industry exhibits a great potential for technological progress, partly following from learning-by-doing. This is not captured by the simple linear function applied in the model. It seems plausible that not taking such effects into account results in that the improvement in average efficiency will be underestimated. However, it is not obvious how to incorporate this into the model, in particular while also retaining its simplicity. 


\section{Concluding remarks}

This paper has addressed policy instruments currently employed to guide the car fleet into becoming more fuel efficient. To provide a structured view on policy instruments, how different instruments interact and how they influence the transition towards a more efficient car fleet, a simple yet informative and transparent model has been designed. In particular, the model captures a view that future car fleet fuel efficiency depends on a series of steps that are linked to each other. Different policy instruments will target different such steps, but they all have the potential to influence the resulting fuel efficiency. The model also focuses on the difference between an initial effect and the outcome in equilibrium stressing the fact that the initial effects typically exceed the equilibrium outcome.

The model has been applied to passenger cars. However, the underlying reasoning of the model is easily transferable to other applications. One such application, which seems close at hand, is the electricity markets and the quest for a more energy efficient system.

As the purpose with this paper is to provide an understanding for how policy instruments work and interact, we have deliberately made a series of highly simplifying assumptions. Thus, the model in its current form is not to be seen as a simulation tool. However, an obvious suggestion for future research is to develop the model such that it better mirrors the real life situation. This requires relaxing some of the assumptions, for instance by allowing for nonlinear functional forms and trying to capture dynamic effects, e.g., related to technological progress, in a better way. This will make the model more complex - and thus less in line with the present paper's purpose - but the outcome of the model will, on the other hand, provide more accurate predictions. 


\section{References}

de Jong Gerard, Fox James, Pieters Marits, Vonk Liese and Daly Andrew (2002) Audit of Car Ownership Models, Report 01192, RAND Europe

DiPasquale Denise and Wheaton William C. (1992) The Markets for Real Estate Assets and Space: A Conceptual Framework, Real Estate Economics, 20(2), pp. 181 - 198

EC (2005) Proposal for a council directive on passenger car related taxes (presented by the Commission), $\operatorname{COM}(2005) 261$ final

EEA (2008) Annual European Community greenhouse gas inventory 1990-2006 and inventory report 2008 Submission to the UNFCCC Secretariat Version 27 May 2008, European Environment Agency Technical report No 6/2008

EPA (2006) Greenhouse Gas Emissions from the US: Transportation Sector 1990-2003, U.S. Environmental Protection Agency Office of Transportation and Air Quality

European Federation for Transport and Environment (2008), CO2 emissions from transport in the EU27 - An analysis of 2006 data submitted to the UNFCCC, August 2008

Fang Audrey Hao (2008) A discrete-continuous model of households' vehicle choice and usage, with an application to effects of residential density, Transportation Research Part B 42, pp. 736-758

Greene David L., Patterson Philip D., Singh Margareth, Li Jia (2005) Feebates, rebates and gas-guzzler taxes: a study of incentives for increased fuel economy, Energy Policy, 33, pp. $757-775$

Kågeson Per (2005) Reducing CO2 emissions fro new cars: A progress report on the car industry's voluntary agreement and an assessment of the need for policy instruments, T\&E 05/1, T\&E - European federation for transport and environment

TemaNord (2008) Trafikafgifter og klimapåvirkning. Nordisk Ministerråd, Köpenhamns, TemaNord 2008:587 
The Swedish Road Administration, (2008) Största minskningen av bränsleförbrukningen på nya bilar någonsin men trots detta ökar utsläppen, PM 2008-03-31 